\title{
Acinar Cell Cystadenoma - a Rarity in Advanced von Hippel-Lindau Disease: A Case Report
}

\author{
Tim Fahlbusch $^{\mathrm{a}} \quad$ Andrea Tannapfel $^{\mathrm{b}}$ Waldemar Uhl ${ }^{\mathrm{a}}$ Chris Braumann ${ }^{\mathrm{a}}$

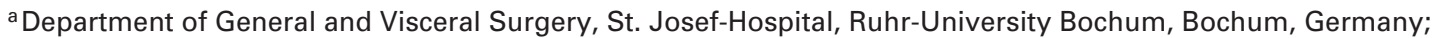 \\ ${ }^{\mathrm{b}}$ Institute of Pathology, Ruhr-University Bochum, Bochum, Germany
}

\section{Keywords}

von Hippel-Lindau disease - Acinar cell cystadenoma . Pancreatic neuroendocrine tumour, pNET

\section{Summary}

Background: Von Hippel-Lindau (VHL) disease may occur at various localisations which can be both intraand extrapancreatic as well as challenging to diagnose by medical imaging. Case Report: A positron emission tomography/magnetic resonance imaging in a 40-yearold woman was performed to monitor a haemangioblastoma. Additionally, it showed findings which were considered to be a pancreatic neuroendocrine tumour (pNET) and retroumbilical metastasis. The suspected metastasis was laparoscopically resected; however, pathological evaluation did not lead to a clear categorisation. Consequently, the pancreatic head was resected in which a pNET and various acinar cell cystadenomas were found. Conclusion: Diagnostic and therapy of advanced VHL disease can be difficult; if in doubt, a surgical approach may establish clarity.

(c) 2017 S. Karger GmbH, Freiburg

\section{Introduction}

Von Hippel-Lindau (VHL) disease is characterized by neoplastic lesions of the central nervous system as well as diverse visceral organs. The estimated incidence is 1 in 36,000 live births [1]. Clinical manifestations can be, among others, central nervous haemangioblastomas, carcinomas of the kidney, pancreatic endocrine cysts and tumours, and pheochromocytomas [2]. The presented case of VHL disease involved a challenging treatment and diagnosis.

\section{Case Report}

A 40-year-old woman suffering from VHL disease presented for evaluation of the findings of a positron emission tomography/magnet resonance imaging (MRI) which was performed to monitor an osteodestructive sacral haemangioblastoma. The results of the imaging showed numerous cystic tumours and a single solid tumour of the pancreas as well as a retroumbilical mass. Consultant radiological opinion considered the solid tumour to be a pancreatic neuroendocrine tumour (pNET) with a retroumbilical metastasis.

Abdominal examination revealed a palpable supraumbilical resistance without tenderness. Computed tomography showed hyperperfused lesions in the pancreatic head which were evaluated as either haemangioblastomas or neuroendocrine tumours (fig. 1). The known sacral haemangioblastoma had grown, and there was no sign of the retroumbilical mass. Additionally, magnet resonance cholangiopancreaticography revealed a large amount of cystic lesions throughout the entire pancreas (fig. 2).

We decided to explore the site laparoscopically. The retroumbilical mass corresponded to a tumour sized $2 \times 3 \mathrm{~cm}$ in the greater omentum, which was resected. Pathological evaluation was difficult due to an uncommon arrangement of immunohistochemical markers. The mass was categorized as either a metastasis of a solid pseudopapillary tumour or as a haemangioma. It was agreed to resect the pancreatic lesion to be able to compare the particular histologic findings and to exclude a possible malignancy.

Therefore, an uneventful pylorus-preserving hemipancreaticoduodenectomy was performed.

Histological evaluation revealed a neuroendocrine tumour which was $1.3 \times$ $1.2 \times 1.2 \mathrm{~cm}$ in size. The TNM classification was pT1, pN0 (0/19), M0, L0, V0, Pn0, R0, G1. The proliferation rate was measured by MIB-1 and accounted for $<1 \%$. Considering these results, the umbilical lesion was re-evaluated and despite the initial assessment classified as a haemangioma. A Sister Mary Joseph nodule could be excluded.

The additional pancreatic cysts were lined with a single-layered epithelium, with the largest one measuring $4.5 \times 3.6 \times 1.5 \mathrm{~cm}$. These lesions were evaluated as acinar cell cystadenomas, although cysts are equivalent to serous cystadenomas in VHL disease (fig. 3).

\section{Discussion}

VHL disease is inherited, and its genetic locus is on the short arm of chromosome 3 [1]. In early stages the disease often remains

\section{KARGER}

(c) 2018 S. Karger GmbH, Freiburg 


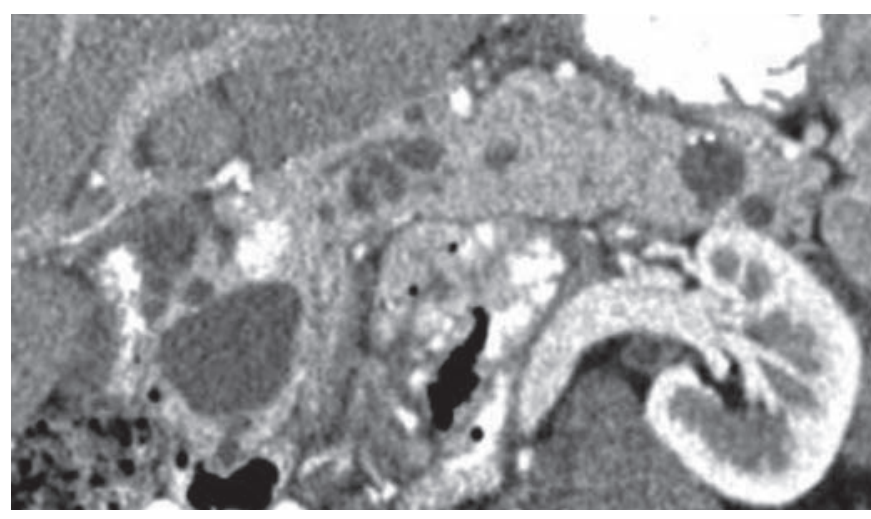

Fig. 1. Computed tomography scan depicting various cystic lesions in the entire pancreas.

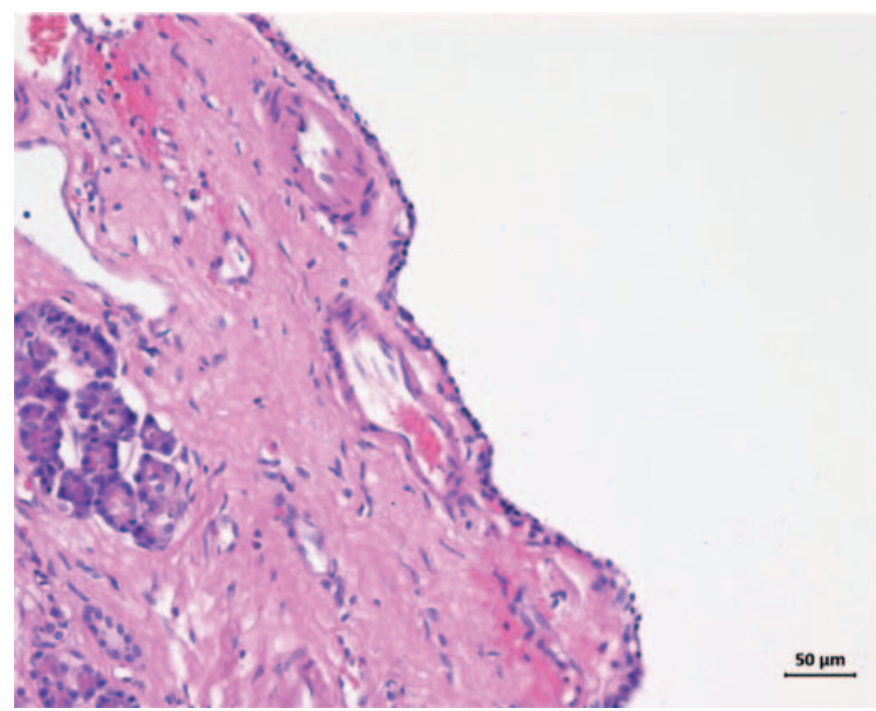

Fig. 3. Histopathological finding of the acinar cell epithelium of the cystadenomas.

asymptomatic; later on, blindness, neurological complications, or death may occur [3].

Pancreatic involvement is diagnosed in $50-80 \%$ of patients with VHL disease [4]. In about $8 \%$ of cases pancreatic manifestations occur solely and are either cystic or solid tumours. Solid masses are mostly neuroendocrine tumours, while cystic lesions are rather simple cysts or serous cystadenomas [5]. Therefore, most pancreatic lesions are benign, but malignant or premalignant tumours such as intrapancreatic mucinous neoplasms or metastases of renal cell carcinoma need to be excluded [6].

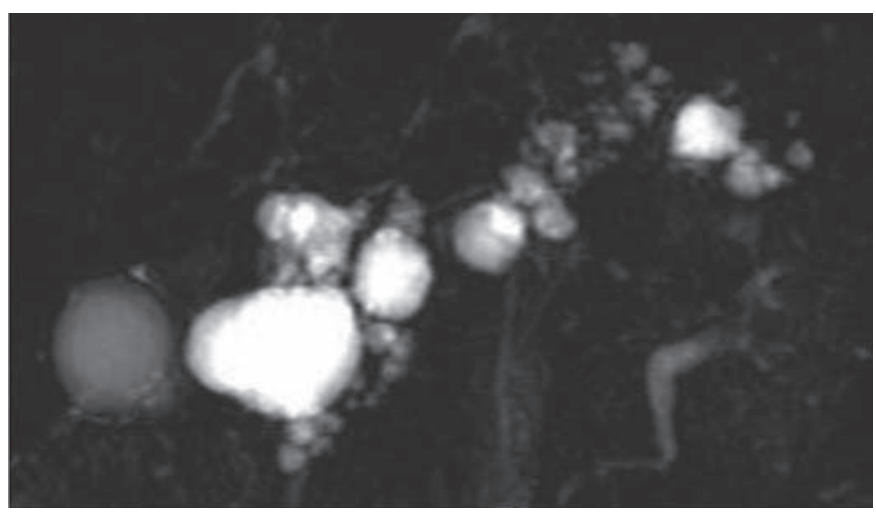

Fig. 2. Magnetic resonance cholangiopancreatography confirming computed tomography results.

$5-17 \%$ of VHL disease patients suffer from pNET [7]. These neoplasms are malignant in $17 \%$ [8]. Most neuroendocrine tumours do not influence physiological processes by secretion of hormones, but there is a risk of dissemination to distant organs or of local advancement. At the time of diagnosis, up to $25 \%$ of the neoplasms have already metastasized [9].

Surgical treatment is recommended for tumours $>2 \mathrm{~cm}$. If the tumour is $<2 \mathrm{~cm}$, resection should only be performed in case of at least G2 grading or if symptomatic, otherwise surveillance by annual MRI scans is advised. Whenever possible, oncological resection is to be aimed for [10]. Advanced stages of a pNET can be treated by chemotherapy, targeted drugs, or peptide receptor radionuclide therapy. For poorly differentiated tumours, G3 platinbased cytostatic agents are used [11].

\section{Conclusion}

pNETs are found in $<17 \%$ of patients with VHL disease. Generally, guidelines recommend a surgical treatment if the tumour is $>2$ $\mathrm{cm}$. In our case, however, a hemipancreaticoduodenectomy needed to be performed despite a pNET tumour size $<2 \mathrm{~cm}$, because metastatic spread could not be excluded in histopathological testing. Additional pancreatic lesions were lined with epithelium and considered as acinar cell cystadenomas.

\section{Disclosure Statement}

The authors declare no conflict of interest.

\section{References}

1 Kim WY, Kaelin WG: Role of VHL gene mutation in human cancer. J Clin Oncol 2004;22:4991-5004.

2 Lonser RR, Glenn GM, Walther M, Chew EY, Libutti SK, Linehan WM, Oldfield EH: von Hippel-Lindau disease. Lancet 2003;361:2059-2067.
3 Binderup MLM, Jensen AM, Budtz-Jorgensen E, Bisgaard ML: Survival and causes of death in patients with von Hippel-Lindau disease. J Med Genet 2017;54:1118.

4 Basturk O, Coban I, Adsay NV: Pancreatic cysts: pathologic classification, differential diagnosis, and clinical implications. Arch Pathol Lab Med 2009;133:423-438.
5 Elli L, Buscarini E, Portugalli V, Reduzzi L, Reduzzi C, Brambilla G, Menozzi F, Bardella MT, Piodi LP, Caldato M, Zambelli A: Pancreatic involvement in von Hippel-Lindau disease: report of two cases and review of the literature. Am J Gastroenterol 2006; 101:26552658. 
6 Charlesworth M, Verbeke CS, Falk GA, Walsh M Smith AM, Morris-Stiff G: Pancreatic lesions in von Hippel-Lindau disease? A systematic review and metasynthesis of the literature. J Gastrointest Surg 2012;16: 1422-1428.

7 Turcotte S, Turkbey B, Barak S, Libutti SK, Alexander HR, Linehan WM, Hughes MS, Nilubol N, Gesuwan K, Millo C, Quezado M, Choyke PL, Kebebew E, Phan GQ: von Hippel-Lindau disease-associated solid microcystic serous adenomas masquerading as pancreatic neuroendocrine tumors. Surgery 2012;152:11061117.
8 Libutti SK, Choyke PL, Bartlett DL, Vargas H, Walther M, Lubensky I, Glenn G, Linehan WM, Alexander HR: Pancreatic neuroendocrine tumors associated with von Hippel Lindau disease: diagnostic and management recommendations. Surgery 1998; 124:1153-1159.

9 Delman KA, Shapiro SE, Jonasch EW, Lee JE, Curley SA, Evans DB, Perrier ND: Abdominal visceral lesions in von Hippel-Lindau disease: incidence and clinical behavior of pancreatic and adrenal lesions at a single center. World J Surg 2006;30:665-669.
10 Falconi M, Eriksson B, Kaltsas G, Bartsch DK, Capdevila J, Caplin M, Kos-Kudla B, Kwekkeboom D, Rindi G, Klöppel G, Reed N, Kianmanesh R, Jensen RT: Consensus guidelines update for the management of functional p-NETs (F-p-NETs) and non-functional p-NETs (NFp-NETs). Neuroendocrinology 2016;103:153-171.

11 Pavel M, O'Toole D, Costa F, Capdevila J, Gross D, Kianmanesh R, Krenning E, Knigge U, Salazar R, Pape U-F, Öberg K: ENETS Consensus Guidelines update for the management of distant metastatic disease of intestinal, pancreatic, bronchial neuroendocrine neoplasms (NEN) and NEN of unknown primary site. Neuroendocrinology 2016;103:172-185. 